\title{
Concentration and composition of gas inclusions in some oxide crystals
}

P. Arhipova, S. Tkachenko ${ }^{\text {a }}$, E. Galenin ${ }^{\mathrm{a}}$, Ia. Gerasymovª, O. Sidletskiy ${ }^{\mathrm{a}, *}$, K. Kudin ${ }^{\mathrm{b}}$,

K. Lebbou ${ }^{\mathrm{c}}$

${ }^{1}$ Institute for Scintillation Materials NAS of Ukraine, 60, Nauky ave., 61001 Kharkiv, Ukraine

${ }^{2}$ State Scientific Institution "Institute for Single Crystals NAS of Ukraine" 60, Nauky ave., 61001 Kharkiv, Ukraine

${ }^{3}$ Institute Lumière Matière, UMR5306 CNRS, Universite de Lyon 1, 69622 Villeurbanne Cedex, France

*Tel.: +380-57-341-0366. Fax: +380-57-340-4474

\begin{abstract}
A method of concentration of gas impurities contained in a melt into sealed cavities in a crystal has been proposed for the first time. This makes it possible to determine the amount of gases dissolved in the melt during crystallization by the Edge-defined Film-fed Growth (EGF) technique and the gas pressure in cavities inside the crystals. We also measure the composition of gas inclusions in crystallized melts of $\mathrm{Al}_{2} \mathrm{O}_{3}, \mathrm{Y}_{3} \mathrm{Al}_{5} \mathrm{O}_{12}$ and $\mathrm{Bi}_{4} \mathrm{Ge}_{3} \mathrm{O}_{12}$ and discuss it in connection with crystal growth procedure and quality of crystals.
\end{abstract}

Keywords: A1. Segregation, A1. Volume defects, A2. Growth from melt, B1. Oxides, B2. Dielectric materials. 


\section{Introduction}

The majority of crystals grown from the melt contain macrodefects comprising gas inclusions or residual micropores. Following the growth technique used, their quantity and distribution over the crystal may vary. The size of visible inclusions ranges from microns to millimeters, and their

shape is mainly spherical or elongated. The presence of inclusions decreases the production yield as crystal parts containing inclusions are inapplicable for further processing. Among the many works on elimination of inclusions, very few of them are focused on inclusion composition. Determination of precise composition of inclusions would help to find out mechanisms of their formation and, finally, to develop advanced procedures to reduce their quantity.

The majority of works on inclusions in crystals deal with sapphire as the most widely produced oxide crystal. A detailed analysis of works on gaseous inclusions in sapphire was made in [1] where the inclusions formation was considered in relation to growth atmosphere composition, admixtures, growth rate, melt overhearing or overcooling, melt hydrodynamics, crystallization interface shape, etc. However, even in this review just growth atmosphere composition and probable chemical reactions with participation of gas phases were indicated.

According to the literature data $[2,3,4]$ and our observations, the gaseous admixtures are captured during the crystallization interface shape evolution, and the orientation of elongated inclusions is dependent on the crystallographic orientation and morphology of the equilibrium and skeleton crystal morphologies. Composition and quantity of gases dissolved in melts depends on the presence of admixtures in the raw material, melt overheating, vapour pressure of melt dissociation products, pressure and composition of growth atmosphere. 
The composition determination of gas sealed in frozen melt pores with a mean size $2 \div 20 \mu \mathrm{m}$ is a rather complex task. Just the qualitative composition of gas admixtures in the frozen melt was determined [1]. However, concentration of gases in the frozen melt probably substantially differs from that in the melt during the crystal growth, because gases dissolved in melt accumulate in the latter due to their segregation at the crystallization interface. Besides this, gases dissolved in the melt may diffuse to the gas atmosphere and back.

In this work a method for determination of pressure and concentration of gases dissolved in the melt, as well as actual composition of gas bubbles formed in single crystals has been proposed. The gas compositions of bubbles in three well-known oxide crystals - $\mathrm{Al}_{2} \mathrm{O}_{3}$, $\mathrm{Bi}_{4} \mathrm{Ge}_{3} \mathrm{O}_{12}(\mathrm{BGO}), \mathrm{Y}_{3} \mathrm{Al}_{5} \mathrm{O}_{12}$ (YAG) obtained under different conditions are determined.

\section{Experimental}

Gaseous inclusions were studied in $\mathrm{Al}_{2} \mathrm{O}_{3}, \mathrm{Bi}_{4} \mathrm{Ge}_{3} \mathrm{O}_{12}(\mathrm{BGO}), \mathrm{Y}_{3} \mathrm{Al}_{5} \mathrm{O}_{12}$ (YAG) crystals grown by the EFG (Edge Defined Film Fed Growth) and in crystalized melts remaining in the crucibles after the Czochralski growth process. Conventional induction heating setups were used in both cases. The crystal shapes were controlled by the weight sensor. $\mathrm{Al}_{2} \mathrm{O}_{3}$ and $\mathrm{Y}_{3} \mathrm{Al}_{5} \mathrm{O}_{12}$ crystals were grown from Mo crucibles under graphite thermal insulation and $\mathrm{Ar}$ atmosphere. $\mathrm{Bi}_{4} \mathrm{Ge}_{3} \mathrm{O}_{12}$ crystals were grown from Pt crucibles under alumina ceramic thermal insulation and air atmosphere.

For growth of sapphire, different crushed crystals grown by Verneuil and Kyropoulos techniques and granulated powders from different vendors were used as the raw materials. To obtain gas cavities with a maximal size, the melt should be saturated with gases as much as possible. For this reason the melt volume should be negligible compared to the growth chamber volume. The latter case is realized in this work, where the melt weight was just $10 \mathrm{~cm}^{3}$ as the maximum in a growth chamber with $360000 \mathrm{~cm}^{3}$ volume. 
YAG crystals were grown using $\mathrm{Al}_{2} \mathrm{O}_{3}$ and $\mathrm{Y}_{2} \mathrm{O}_{3}$ raw materials in the powder form. $\mathrm{BGO}$ crystals were grown using $\mathrm{Bi}_{2} \mathrm{O}_{3}$ and $\mathrm{GeO}_{2}$ raw materials that were first reacted by a solid state reaction. The analysis of gas composition in crystallized melts was carried out using a self-made chamber for sample destruction under load, which was connected to a mass spectrometer by the same scheme.

Compositions of gaseous cavities in single crystals and crystallized melts were determined by an IPDO-2 mass spectrometer. A crystal with a sealed gaseous cavity was placed in a copper thin-wall tube, sealed from one side. The tubes were previously heated for removal of water. The tube with the sample was connected to the mass spectrometer via a leak valve and then pumped down to a pressure of about $4 \mathrm{~Pa}$. Then the leak was opened towards the mass spectrometer vacuum camera (working pressure $10^{-4}-10^{-5} \mathrm{~Pa}$ ) and background spectrum was registered. Then the sample was fragmented by bending the copper tube. Gases released after the cavity unsealing were analyzed in the mass spectrometer by the omegathrone-type gauge determining their partial pressures. The compositions of the gases desorbed from the samples were determined by deducing the background from the obtained values.

Fig. 1.

\section{Results}

\subsection{Concentration and sealing of gaseous admixtures in $\mathrm{Al}_{2} \mathrm{O}_{3}$ melt.}

To evaluate the quantity and composition of gases dissolved in the melt, the gases were concentrated into the cavity inside the $\mathrm{Al}_{2} \mathrm{O}_{3}$ crystals. The crystals were grown by the EFG technique with Mo shaper with the melt feeding channel at the periphery (Fig. 2). The shaper upper interface is curved and contains a barb in the center. The shaper outer diameter is $5 \mathrm{~mm}$, 
and the barb height over the shaper surface is $1.2 \mathrm{~mm}$. A circular feeding channel of $0.25 \mathrm{~mm}$ width was made at a diameter of $4.25 \mathrm{~mm}$.

Fig. 2.

Following the shaper construction, the melt flows from the feeding channel to the center of the shaper upper surface. Due to segregation by the crystallization interface, gaseous admixtures in melt were concentrated in the crystal center forming a column of microbubbles (Fig. 3a). Then the melt film thickness at the shaper was minimized by decreasing the heating power, coming close to the crystal freezing to the shaper. As the growth process is controlled by the weight sensor, the weight increment does not change at constant melt film thickness and diameter. A decrease of the film thickness or diameter results in weight increase due to the Laplace pressure. Under the minimal achieved film thickness the weight oscillations amplitude reached 10-15 g. Under constant heating power the gaseous admixtures were concentrated into such an elongated cavity in the crystal center (Fig. 3, 4). After achieving the required length, the cavity was sealed (Fig. 3d, 4d) by the heater power increase. If necessary, several cavities can be formed in a single growth run. The cavity formation was also controlled visually by a video camera.

Fig. 3

Fig. 4 
The cavity dimensions vary in the samples obtained from the different batches of $\mathrm{Al}_{2} \mathrm{O}_{3}$ raw materials. The cavities were not formed in the crystals recrystallized from crushed parts of crystals grown by the Kyropoulos technique in vacuum (Fig. 5a). In the crystals grown from powders and from ground crystals fabricated by the other techniques the cavity diameter reached $1.7 \mathrm{~mm}$. The cavity walls were not smooth, but had screw-shaped grooves (see Fig. 4a). Dark areas around the cavity (Fig. 4 b,c) we attribute to some admixtures accumulated there due to segregation at the crystallization interface.

Fig. 5

Admixture content in the used $\mathrm{Al}_{2} \mathrm{O}_{3}$ raw material batches was similar within the $1 \times 10^{-4} \div 1 \times 10^{-3}$ wt.\% range. In the crystals with the maximal cavity dimensions the $\mathrm{Fe}$ and $\mathrm{Cu}$ concentrations exceeded the average value and reached $1 \times 10^{-2}$ wt.\%. However, we have not succeeded in determining the exact factors affecting the cavity size and admixtures segregation.

At the cavity maximal diameter of $1.7 \mathrm{~mm}$ its volume is about $13 \%$ of the total crystal volume that shows there is a significant amount of gas inside. To evaluate the gas pressure inside the cavity during the crystal growth, the cavity in the resulting crystal was opened by scoring the sample dipped into water. As temperatures in cavities are high, pressures are rather low, and any of the component gases in a mixture is not near its condensation point, the gases behaviour in cavities can be described quite closely by the ideal gas law. If the pressure inside the cavity was atmospheric during the cavity formation, gas volume should decrease by $\sim 7.4$ times under cooling in accordance with the Gay-Lussac's law (formulae 1, assuming no chemical reactions between gases, for example, $\mathrm{CO}+\mathrm{O}_{2} \rightarrow \mathrm{CO}_{2}$ or $\mathrm{H}_{2}+\mathrm{O}_{2} \rightarrow \mathrm{H}_{2} \mathrm{O}$ reactions), and the cavity should be partially filled with water: 


$$
V_{1} \cdot T_{2}=V_{2} \cdot T_{1} \rightarrow V_{2}=\frac{V_{1} \cdot T_{2}}{T_{1}}=V_{1} \frac{293}{2173} \approx \frac{V_{1}}{7.4} ;(1)
$$

Therefore, for a cavity length of $74 \mathrm{~mm}$, just around $10 \mathrm{~mm}$ will remain filled with gas. Actually, after opening the $74 \mathrm{~mm}$ long cavity just a small volume with the length less than 0.5 mm was not filled with water (Fig. 6).

Therefore, the pressure inside the cavity is about 20 times $(10 \mathrm{~mm} / 0.5 \mathrm{~mm})$ lower than the atmospheric pressure, i.e. $\sim 5 \mathrm{kPa}$. The phenomenon of low pressure in the cavity is confirmed by the observation of the melt pulled inside the cavity by $4 \mathrm{~mm}$ during the cavity sealing (Fig. $6 \mathrm{~b}$ ). After the sealing the bubbles were distributed over the crystal and formed the periodic inclusions (striations) following the shape of the concave crystallization interface.

In the considered example the gas volume in the cavity after its opening was:

$$
V_{1}=\pi \cdot r_{2}^{2} \cdot l=3.14 \cdot 0.85^{2} \cdot 0.5 \approx 1.1 \mathrm{~mm}^{3}
$$

where $r_{2}$ - cavity radius, $l$ - length of the portion filled with gas after the cavity opening.

At a temperature of $2173 \mathrm{~K}$ and atmospheric pressure of $0.1 \mathrm{MPa}$ this amount of gas should fill a volume of $8.2 \mathrm{~mm}^{3}$.

$$
V_{g 1}=\frac{V_{g 2} \cdot T_{1}}{T_{2}}=V_{g 2} \frac{2173}{293}=1.1 \cdot 7.4 \approx 8.2
$$

Such a quantity of dissolved gas flashes out from the melt with the volume:

$$
V_{g 2}=s \cdot l \cdot\left(\frac{\rho_{c r}}{\rho_{m l t}}\right)=\pi\left(r_{1}^{2}-r_{2}^{2}\right) \cdot l \cdot\left(\frac{\rho_{c r}}{\rho_{m l t}}\right)=3.14 \cdot\left(2.5^{2}-0.85^{2}\right) \cdot 74 \cdot \frac{4}{3} \approx 1730
$$

where $s$ - crystal cross-section square; $r_{1}$ и $r_{2}$ - crystal and cavity radii; $l$ - cavity length; $\rho_{c r}$ - crystal density; ${ }^{\rho_{m l t}}-$ melt density.

Consequently, the bulk ratio of gas dissolved in the melt is: 


$$
\frac{V_{g}}{V_{m}}=\frac{8.2}{1730} \approx 0.0047
$$

i.e. the melt contains $\sim 0.47 \%$ vol. of dissolved gas. Note that this value is evalueated for the maximal cavity diameter of $1.7 \mathrm{~mm}$ among the growth crystals. In the rest of grown crystals the cavity diameter ranged from 0.5 to $1.1 \mathrm{~mm}$, and, consequently, $\mathrm{V}_{\mathrm{g}}$ is smaller.

Fig. 6

\subsection{Gas composition study.}

After crystal growth by the Czochralski method a part of the crystallized melt remains in the crucible. Obviously, the crystallized melt contains more dissolved gas than the crystal, because most gas admixtures are segregated into the melt during crystallization. The gaseous admixtures in $\mathrm{Al}_{2} \mathrm{O}_{3}$ crystallized melt pores were studied in [5] by the same method. In the current work, besides $\mathrm{Al}_{2} \mathrm{O}_{3}$, we also measured the gas content in crystallized melts of YAG and BGO.

As an example, the mass spectrum of gas cavities in a YAG crystallized melt is presented in Fig. 7. The compounds corresponding to each peak are labeled. The weak unidentified peak at $\mathrm{M} / \mathrm{e}=34$, probably, corresponds to some organics. The gases having the same molecular weights $\mathrm{M}$, for example, $\mathrm{N}_{2}$ and $\mathrm{CO}(\mathrm{M} / \mathrm{e}=28)$ were identified by their molecular benchmarks. The nitrogen spectrum is always accompanied by a peak at $\mathrm{M}=14$ (quantity of electrons) corresponding to atomic nitrogen, while the $\mathrm{CO}$ spectrum has a peak at $\mathrm{M}=12$ corresponding to atomic carbon. Probabilities of the benchmarks for every compound are constant thus providing the determination of concentration of each compound by the amplitude of the benchmark peaks. The results of mass-spectrometric measurements are summarized in Table 1. 
Fig. 7

Table 1.

\section{Discussion}

As the parts of previously grown crystals without inclusions were taken as raw materials for the $\mathrm{Al}_{2} \mathrm{O}_{3}$ crystal growth, the raw materials could not be the basic origin of gaseous admixtures in the melt. Therefore the gaseous admixtures were introduced into the melt during crystallization. Probably, residual gases adsorbed inside the growth chamber, admixtures in Ar gas, and melt dissociation products are the basic origin of the contamination. As the correlation between the cavity diameter and type of raw material was noticed, admixtures promote the gas dissolving into the melt. Besides some variation of the gas composition in different samples (see Table 1), nitrogen and oxygen are the main gas admixtures in $\mathrm{Al}_{2} \mathrm{O}_{3}$, which is in agreement with the data in [5]. The significant $\mathrm{H}_{2} \mathrm{O}$ content variation is probably related to the presence of oxygen and hydrogen in the $\mathrm{Al}_{2} \mathrm{O}_{3}$ melts and the reaction $\mathrm{H}_{2}+\mathrm{O}_{2} \rightarrow \mathrm{H}_{2} \mathrm{O}$ during cooling.

In YAG, nitrogen and oxygen are also the basic gaseous admixtures. The admixtures content is similar in the studied samples, because the raw materials for crystal growth were prepared in the same way. Nitrogen in the YAG melt can be introduced from the raw material, or by diffusion of gases adsorbed within the thermal insulation. The presence of hydrocarbons is related to the presence of yttrium carbide in the melt [6] and their interaction with water vapours during cooling.

In $\mathrm{BGO}$, apart from nitrogen and oxygen, the oxygen content is higher than that in $\mathrm{Al}_{2} \mathrm{O}_{3}$ and YAG. The latter is evidently caused by growth in an air atmosphere and the addiction of bismuth to form an unstable oxide with higher valence (V). At the same time, the nitrogen content in the 
BGO melt does not exceed those in $\mathrm{Al}_{2} \mathrm{O}_{3}$ and $\mathrm{YAG}$ despite the high nitrogen content in air. There are many data on crystal growth in $\mathrm{N}_{2}$ atmospheres, however, no oversaturation of a melt with nitrogen has been observed anywhere [7, 8], because its solubility in melts is limited. Nitrogen is introduced into oxide melts mainly from the raw materials, or admixtures in raw materials promote the nitrogen dissolving in melts.

\section{Conclusions}

Concentrations of gases in an $\mathrm{Al}_{2} \mathrm{O}_{3}$ melt during crystal growth were evaluated for the first time by the intentional formation of gas cavities in crystal during the EFG process. The gas concentration in melts obtained from powdered raw material reaches $0.47 \mathrm{vol} \%$. The cavities were not formed during recrystallization of previously grown crystals, which points at reduction of gas content in the melt.

The composition of gases in the crystals of $\mathrm{Al}_{2} \mathrm{O}_{3}$ and crystallized YAG and $\mathrm{BGO}$ melts was determined. Gaseous admixtures are introduced into melts not only by raw materials, but also from residual gases adsorbed inside the growth chamber, admixtures in the growth atmosphere, and melt dissociation products. Besides the basic admixtures of oxygen and nitrogen, the gases in melts crystallized under the presence of graphite thermal insulation contain up to $3.27 \%$ of CO. Meanwhile, a higher amount of Ar and oxygen is contained in melts under Ar and air growth atmospheres, correspondingly. Trace amounts of $\mathrm{CO}_{2}, \mathrm{H}_{2} \mathrm{O}$ and hydrocarbons were also detected. Relatively low $\mathrm{N}$ concentration in gas dissolved in the BGO melt despite its high content in air suggests that nitrogen solubility in melts is limited. $\mathrm{N}$ content correlates with the raw material preparation procedure (powder or crushed crystals).

Therefore the proposed procedure of cavity formation is a tool to control the quantity of gases dissolved in melts. Analysis of ways of introduction of gas admixtures into the melt is necessary for minimization of bubble concentration in crystals. 


\section{Acknowledgements}

The work is partially supported by the Ukrainian-French PICS project between CNRS (Project No.6598) and National Academy of Sciences of Ukraine (Project F1-2016) and Marie Skłodowska-Curie Research, Innovation Staff Exchange Project H2020-MSCARISE- 2014no.644260 “INTELUM”.

\section{References}

[1] O. Bunoiu, Th. Duffar, I. Nicoara, Prog. Cryst. Growth Charact. Mater. 56 (2010) 123145.

[2] V. Kanevsky, E. Krivonosov, L. Litvinov, Funct. Mat. 6 (1999) 370-373.

[3] V. Kanevsky, E. Krivonosov, L. Litvinov, Funct. Mat. 6 (1999) 636-639.

[4] A. Boyarintsev, E. Galenin, V. Nagornyak, A. Palamar, S. Tkachenko, Poverkhnost (J. Surf. Invest.: X-ray, Synchrotron Neutron Tech.) 12 (2007) 99-102 (in Russian).

[5] T. Yalovets, V. Borodin, A. Lesznev, G. Sikharulidze, T. Steriopolo, V. Tatarchenko, Neorganicheskie Materialy, 21 (1985) 262-264 (in Russian).

[6] P. Arhipov, S. Tkachenko, S. Vasyukov, K. Hubenko, Ia. Gerasymov, V Baumer, A. Puzan, P. Mateychenko, K. Lebbou, O. Sidletskiy, J. Cryst. Growth 449 (2016) 104-107.

[7] Y. Fujimoto, T. Yanagida, H. Yagi, Yanagidani, V. Chani, Opt. Mat. 36 (2014) 19261929.

[8] F. Selim, D. Solodovnikov, M. Weber, and K. Lynn, App. Phys. Lett. 91 (2007) 104105. 


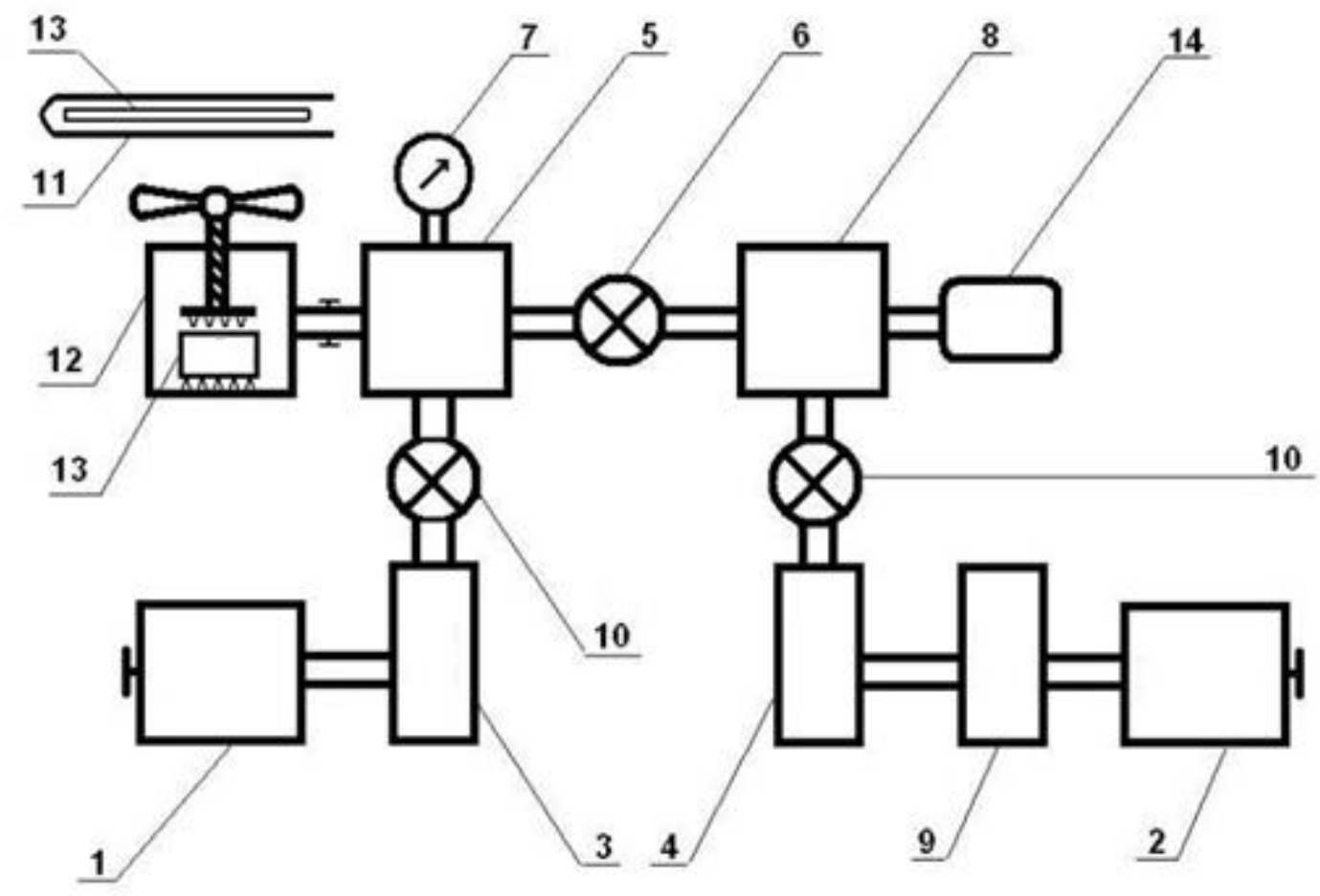

Fig. 1. Scheme of the setup for determination of gaseous cavities composition: 1,2-backing forevacuum pumps; 3, 4 - nitrogen traps; 5 - separation chamber; 6 - adjustable valve; 7 pressure indicator; 8 - mass-spectrometer chamber; 9 - diffusion pump; 10 - valve; 11 - copper tube with sample; 12 - chamber for sample destruction under load; 13 - sample; 14 - mass spectrometer sensor (omegathrone-type gauge determining gas components partial pressures). 


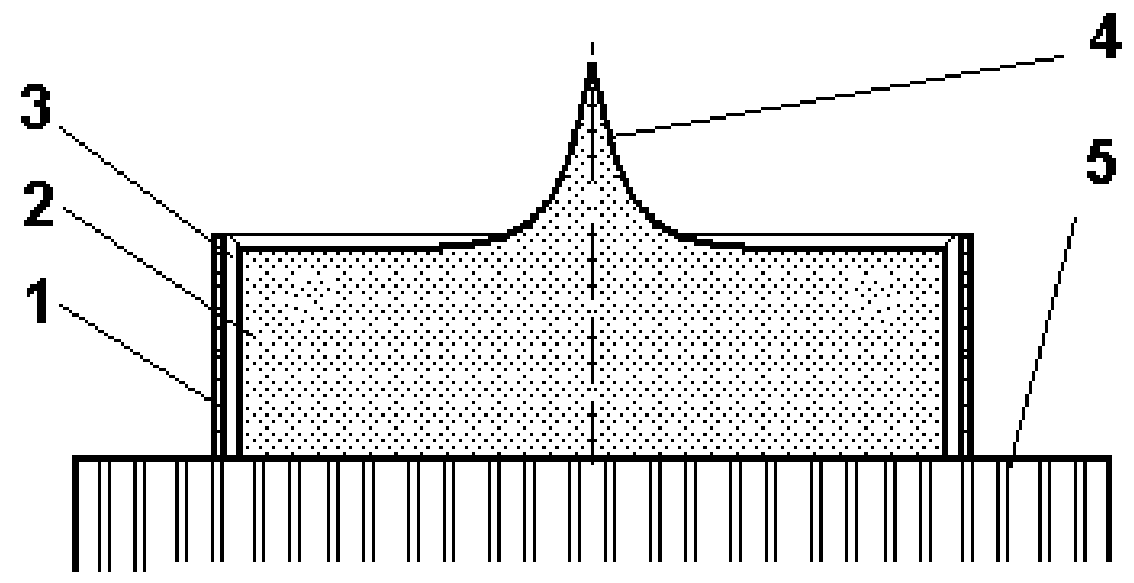

Fig. 2. A sketch of shaper for EFG process: 1 - outer ring, 2 - inner part, 3 - melt feeding channel, 4 - conical barb, 5 - pedestal with capillary system. 


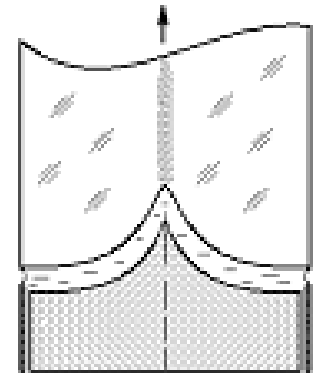

a

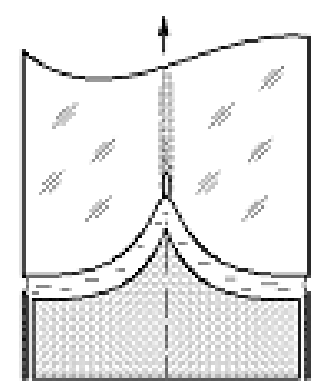

b

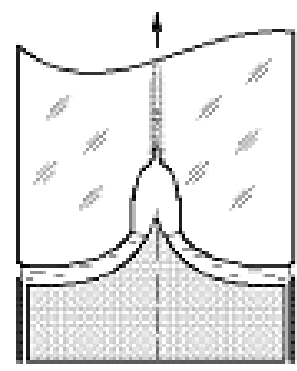

C

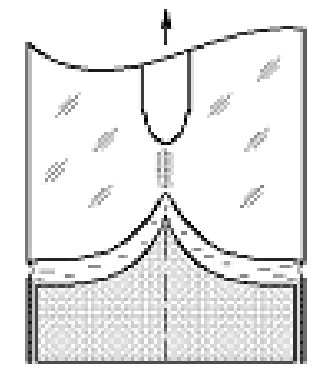

d

Fig 3. Stages of the cavity formation in crystal: a- column of separate inclusions, $b$ - gas bubble appearance, $\mathrm{c}$ - cavity formation, $\mathrm{d}$ - cavity sealing. 
a

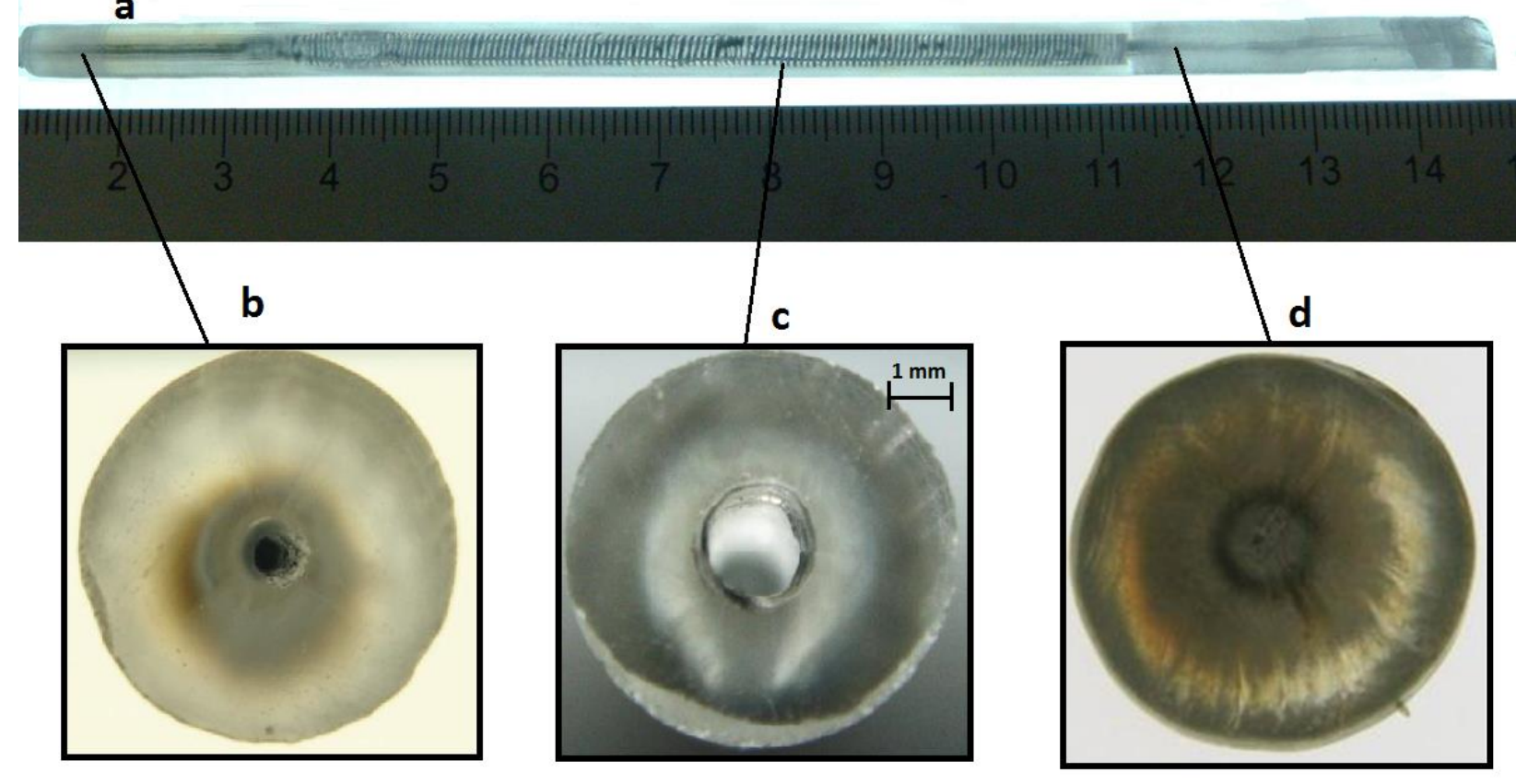

Fig. 4. Longitudinal view of $\mathrm{Al}_{2} \mathrm{O}_{3}$ crystal with intentionally created cavity inside (a), and enlarged view of the section transverse cuts of this crystal: at the beginning of cavity (b), in the section with maximal cavity diameter (c), sealing of the cavity (d). 
a

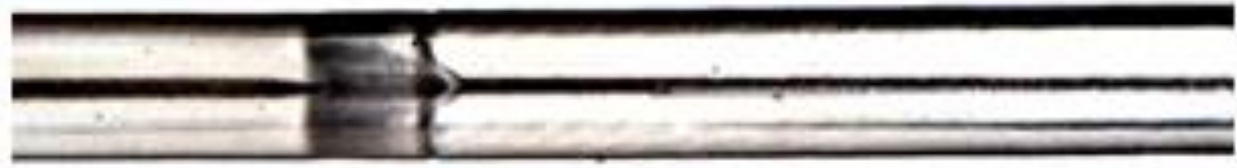

b

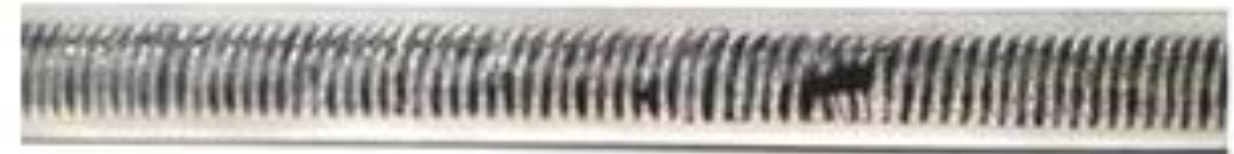

C

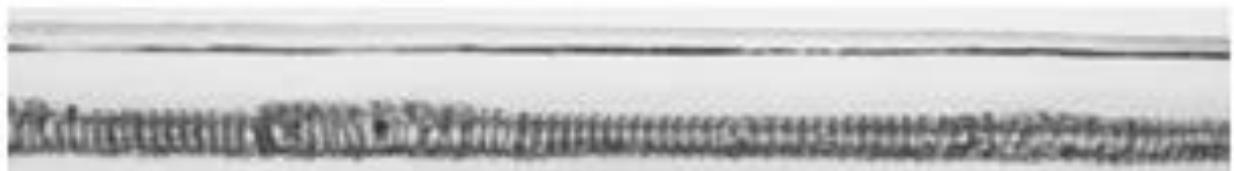

Fig. 5. Cavity sizes and shapes in $\mathrm{Al}_{2} \mathrm{O}_{3}$ crystals obtained from different raw materials: a ground crystals fabricated by the Kyropoulos technique in vacuum, b - powder, $\mathrm{c}-$ ground crystals fabricated by the Verneuil technique. 


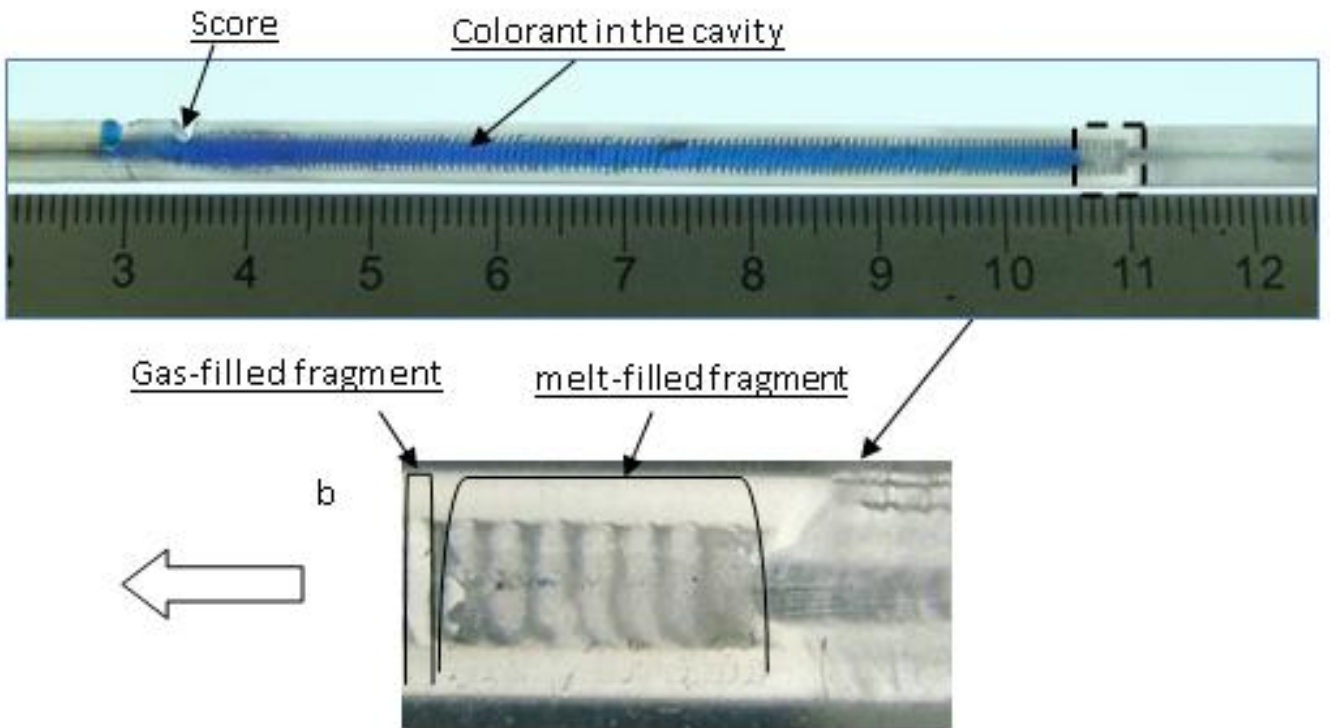

Fig. 6. Cavity filled with the colorant and the enlarged view of the cavity fragment filled with melt during the cavity sealing. The thick arrow denotes the crystal pulling direction. 


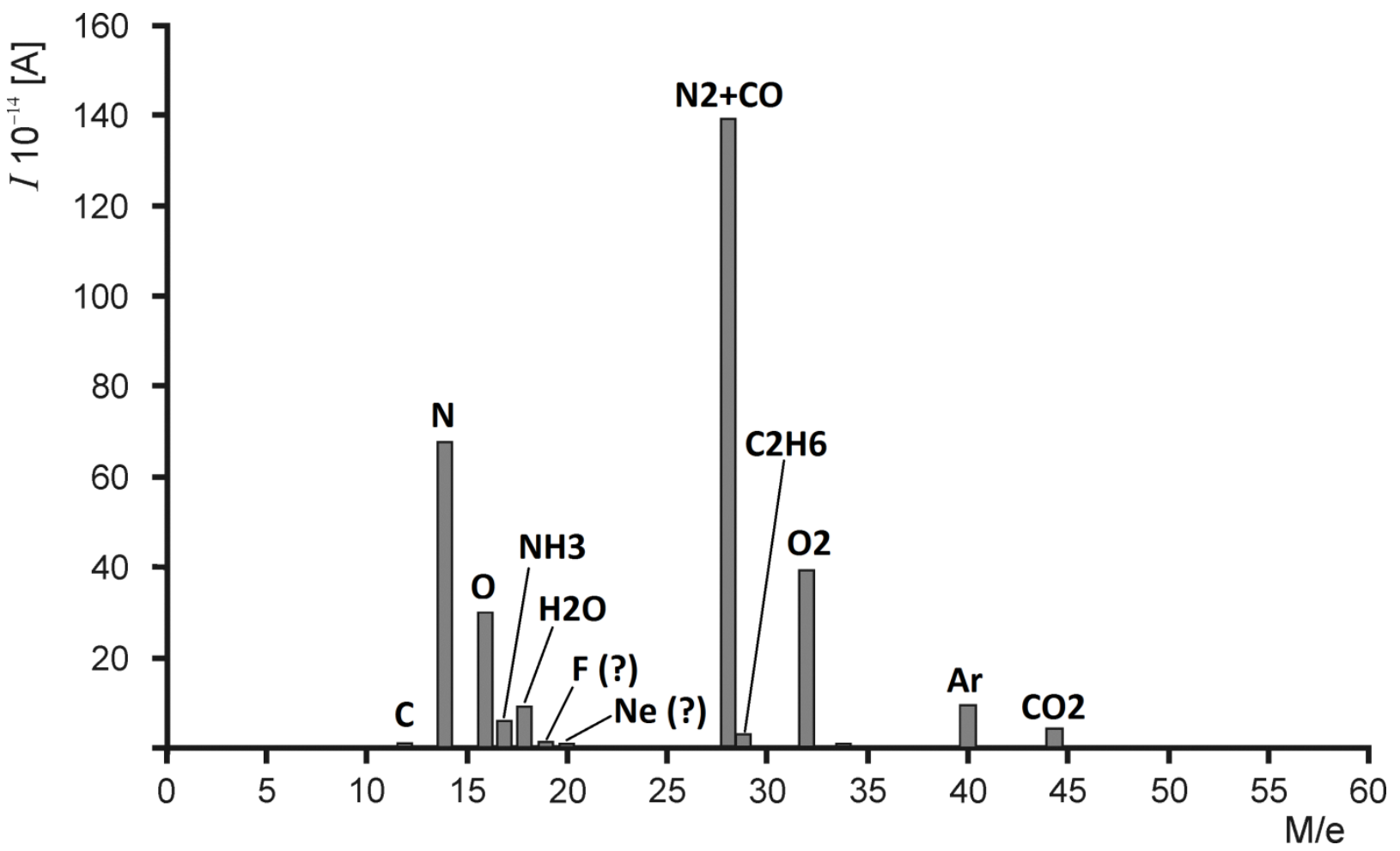

Fig.7. Mass-spectrum of gas cavities in YAG crystallized melt (the background is not deduced). 
Table 1. Composition of gas in cavities.

\begin{tabular}{|c|c|c|c|c|c|c|c|}
\hline & \multicolumn{7}{|c|}{ Gas composition (\%wt.) } \\
\cline { 2 - 8 } & $\mathrm{CO}_{2}$ & $\mathrm{Ar}$ & $\mathrm{O}_{2}$ & $\mathrm{~N}_{2}$ & $\mathrm{CO}$ & $\mathrm{H}_{2} \mathrm{O}$ & $\mathrm{CH}_{4}\left(\mathrm{C}_{x} \mathrm{H}\right)$ \\
\hline \multicolumn{7}{|c|}{ Cavities in $\mathrm{Al}_{2} \mathrm{O}_{3}$ crystal } \\
\hline $\begin{array}{c}\text { Growth } \\
\text { atmosphere }\end{array}$ & 0.06 & 99.22 & - & 0.51 & 0.21 & - & \\
\hline Sample & $0.6 \div 1.2$ & $0.7 \div 1.9$ & $8.2 \div 26.3$ & $59.5 \div 76.0$ & $0.6 \div 1.8$ & $3.8 \div 9.3$ & \\
\hline \multicolumn{7}{|c|}{ Cavities in YAG crystallized melt } & - \\
\hline $\begin{array}{c}\text { Growth } \\
\text { atmosphere }\end{array}$ & - & 99.999 & - & - & - & - & $0.2 \div 0.6$ \\
\hline Sample & - & $2.7 \div 4.0$ & $14.8 \div 18.8$ & $77.3 \div 78.6$ & $0 \div 3.3$ & $0 \div 0.3$ & \\
\hline \multicolumn{7}{|c|}{ Cavities in BGO crystallized melt } & \\
\hline $\begin{array}{c}\text { Growth } \\
\text { atmosphere }\end{array}$ & 0.046 & 1.292 & 23.15 & 75 & - & $\mathrm{ND}$ & \\
\hline Sample & $0.5 \div 0.8$ & $0.8 \div 1.2$ & $33.4 \div 52.8$ & $45.4 \div 63.6$ & $0 \div 0.2$ & $0 \div 0.4$ & \\
\hline
\end{tabular}

